\title{
Therapeutic bronchoscopy in malignant central airway obstruction: is technical success always clinically relevant?
}

\author{
Hervé Dutau ${ }^{1}$, Nicolas Guibert ${ }^{2}$ \\ ${ }^{1}$ Thoracic Oncology, Pleural Diseases and Interventional Pulmonology Department, North University Hospital, Marseille, France; ${ }^{2}$ Interventional \\ Pulmonology Unit, Pulmonology Department, Hôpital Larrey, Toulouse, France \\ Correspondence to: Hervé Dutau. Thoracic Oncology, Pleural Diseases and Interventional Pulmonology Department, North University Hospital, \\ Marseille, France. Email: hdutau@ap-hm.fr.
}

Submitted Jan 12, 2022. Accepted for publication Feb 16, 2022.

doi: $10.21037 /$ jtd-22-52

View this article at: https://dx.doi.org/10.21037/jtd-22-52

Therapeutic bronchoscopy (TB), and more largely interventional pulmonology, is a medical discipline mainly based on empirical knowledge coming from experts' opinions, retrospective studies, registries and very few prospective and even less randomized studies. In fact, any new prospective study, even though with important limitations, that adds scientific evidence is welcome. The conclusions of the study by Freitas et al. (1) may sound redundant with what we think to know from our experience and daily practice in malignant central airway obstruction (MCAO). Indeed, naïve patients from oncologic treatment have longer survival rates, purely endoluminal lesions are easier to treat endoscopically, and the technical success is higher when distal airway and lung parenchyma are visible on computed tomography (CT) scans before the procedure. However, this paper has the merit to assess it in a prospective way. The empirical and theoretical factors allowing for a technical success of TB in patients suffering from MCAO are rather well defined: the obstruction has to be symptomatic (i.e., dyspnea) because the procedure is a symptomatic one, the obstruction has to be located in the main airway (trachea, main stem bronchi, bronchus intermedius essentially) and has to be limited distally in length so that, after reopening, safe airway and functional parenchyma can be found and a stent can eventually cover all the malignant area. In addition, pulmonary arteries have to be functional (in order to prevent a pulmonary dead space) and patients need a performance status sufficient enough to enjoy the clinical benefit. This prerequisite for the technical success of TB, even though mainly empirical, is already largely applied, in the selection of patients, given the high percentage of success reported in about $85-90 \%$ by the operators in the literature (2-9).

However, there is still a significant difference in terms of technical and clinical success of the procedure. Ost et al., in the American registry, showed that technical success of TB was $93 \%$ while the symptoms and the quality of life (QOL) had improved in $48 \%$ and $42 \%$ respectively (3).

One of the main limitations of the study by Freitas et al., is that there is no data regarding symptoms and QOL. Again, TB is a symptomatic procedure and without significant symptoms, the procedure should not be undergone. The main symptom is dyspnea. In quite a recent randomized and prospective study (10), all patients were technical successes from the procedure (airway lumen $>50 \%$ after debulking, a pathologic area that could be entirely covered by a stent if needed, and safe bronchi distal to the obstruction). The mean Borg' scale score of the patients was 7, which represents a severe dyspnea. Realistically, it seems that the higher the dyspnea is, the better the clinical benefit will be.

With a similar radiological pattern of total lung atelectasis, two clinical patterns can be found. In the first one, a severe dyspnea generally represents the sudden obstruction of a main stem bronchus leading to previously functional lung parenchyma. In the second pattern, a progressive dyspnea, or a dyspnea only on exertion, will more likely be secondary to a malignancy evolving from the periphery of the lung to the central airway. Complete atelectasis of a lung can produce significant intrapulmonary shunt. In case of failure of the hypoxic vasoconstriction (Euler-Liljestrand reflex), severe hypoxemia can be observed 
that do not respond to supplemental oxygen. Even a partial re-opening of these lungs can tremendously improve dyspnea.

The extreme clinical situation is represented by patients requiring invasive or non-invasive mechanical ventilation for respiratory distress. These patients represent those who will probably benefit the most from TB and in the vast majority are weaned from mechanical ventilation thanks to TB $(3,11,12)$.

In the case of lobar obstruction, $\mathrm{TB}$ is recommended in order to control bleeding or draining a post-obstructive pneumonia, because ventilation does not significantly improve these cases (13).

The role of invasion, or not, of the pulmonary arteries is crucial in the evaluation of the potential clinical success of TB. In the case of documented pulmonary artery thrombosis, debulking is associated with a risk of an enhanced dead space effect (14).

Patient characteristics are crucial in considering bronchoscopic management, with the aim to avoid invasive techniques in patients who will not benefit from them and select those who will gain benefits. In a retrospective study, prognostic factors (histology, TNM stage, ASA score and previous treatment) allow the determination of patient subgroups that appear to benefit the most from the treatment. The median life expectancy of these patients was generally quite limited to 4.7 months, with great variability (13 months for previously untreated squamous cell carcinomas to less than 1 month for ASA 4 adenocarcinomas) (7).

The procedure-related mortality rate, which is none in Freitas study (1), is generally low with TB, however, reaching $1.9 \%$ mainly for patients with metastatic disease whose general status is extremely altered (7). Metastatic patients (relative risk 1.83) with a poor general status (anaesthetic score ASA 4, relative risk 2.57) seem to be poor candidates. Despite having chemosensitive tumours, their poor prognosis (relative risk 1.7 for large cell carcinoma and 1.55 for small cell carcinoma) leads to this candidate inadequacy (7).

Naïve patients from any oncologic treatment seem to have a better survival, although it is not always the case. Guibert et al. (7) found that survival in previously treated patients to be significantly better when compared with that of untreated patients (relative risk 0.53), even after taking into account the adjustment of other prognostic factors. This supports the idea that TB should not be considered as a last chance procedure after having exhausted all other treatments. TB must be included in multimodal management and combined with specific treatments to improve their tolerability (e.g., post-obstructive pneumonia drainage before chemotherapy and potential aplasia, relieving atelectasis in order to consider radiotherapy).

All these potential prognostic factors must be validated prospectively. This will enable a more precise evaluation of the effectiveness of TB in terms of survival and quality of life (QOL). It will also allow the identification of patient subgroups that will benefit from a better QOL and a longer survival. A prospective study on 947 patients evaluated QOL after TB of MCAO (3). Health-related QOL (SF-6D) was improved in 76 (42\%) out of 183 patients measured. In the SPOC trial a dramatic improvement of QOL [Quality of Life 30 Lung Cancer 13 (QLC 30 LC-13)] was observed in both arms, with a more sustained effect in the stent arm (10). So far, only two small studies have evaluated the effectiveness of a multimodal TB on QOL. Amjadi et al. (15) showed, in 20 patients, an improvement of the dyspnea score, but not in the overall QOL score measured by the EORTC (European Organisation for Research and Treatment of Cancer) score. The second study, involving 37 patients, failed to find a significant improvement in the overall score (EORTC LC13) either (16).

In conclusion, thanks to Freitas et al. (1), some questions regarding predictors of technical success of TB in MCAO have now found answers in a prospective way, but many other prospective studies need to be performed to answer all the remaining questions related to the clinical success, improvement in QOL, the timing of TB in the multimodal oncologic management, and to the identification of the characteristics of the gold responding patients.

\section{Acknowledgments}

We thank Mrs. Aniko Fleming for the English edition. Funding: None.

\section{Footnote}

Provenance and Peer Review: This article was commissioned by the editorial office, Fournal of Thoracic Disease. The article has undergone external peer review.

Peer Review File: Available at https://jtd.amegroups.com/ article/view/10.21037/jtd-22-52/prf

Conflicts of Interest: Both authors have completed the ICMJE 
uniform disclosure form (available at https://jtd.amegroups. com/article/view/10.21037/jtd-22-52/coif). HD reports that he is a consultant for Novatech SA. The other author has no conflicts of interest to declare.

Etbical Statement: The authors are accountable for all aspects of the work in ensuring that questions related to the accuracy or integrity of any part of the work are appropriately investigated and resolved.

Open Access Statement: This is an Open Access article distributed in accordance with the Creative Commons Attribution-NonCommercial-NoDerivs 4.0 International License (CC BY-NC-ND 4.0), which permits the noncommercial replication and distribution of the article with the strict proviso that no changes or edits are made and the original work is properly cited (including links to both the formal publication through the relevant DOI and the license). See: https://creativecommons.org/licenses/by-nc-nd/4.0/.

\section{References}

1. Freitas C, Serino M, Cardoso C, et al. Predictors of survival and technical success of bronchoscopic interventions in malignant airway obstruction. J Thorac Dis 2021;13:6760-8.

2. Shin B, Chang B, Kim H, et al. Interventional bronchoscopy in malignant central airway obstruction by extra-pulmonary malignancy. BMC Pulm Med 2018;18:46.

3. Ost DE, Ernst A, Grosu HB, et al. Therapeutic bronchoscopy for malignant central airway obstruction: success rates and impact on dyspnea and quality of life. Chest 2015;147:1282-98.

4. Razi SS, Lebovics RS, Schwartz G, et al. Timely airway stenting improves survival in patients with malignant central airway obstruction. Ann Thorac Surg 2010;90:1088-93.

5. Kim BG, Shin B, Chang B, et al. Prognostic factors for survival after bronchoscopic intervention in patients with airway obstruction due to primary pulmonary malignancy. BMC Pulm Med 2020;20:54.

6. Jeon K, Kim H, Yu CM, et al. Rigid bronchoscopic

Cite this article as: Dutau H, Guibert N. Therapeutic bronchoscopy in malignant central airway obstruction: is technical success always clinically relevant? J Thorac Dis 2022;14(3):794-796. doi: 10.21037/jtd-22-52 intervention in patients with respiratory failure caused by malignant central airway obstruction. J Thorac Oncol 2006;1:319-23.

7. Guibert N, Mazieres J, Lepage B, et al. Prognostic factors associated with interventional bronchoscopy in lung cancer. Ann Thorac Surg 2014;97:253-9.

8. Stratakos G, Gerovasili V, Dimitropoulos C, et al. Survival and Quality of Life Benefit after Endoscopic Management of Malignant Central Airway Obstruction. J Cancer 2016;7:794-802.

9. Giovacchini CX, Kessler ER, Merrick CM, et al. Clinical and radiographic predictors of successful therapeutic bronchoscopy for the relief of malignant central airway obstruction. BMC Pulm Med 2019;19:219.

10. Dutau H, Di Palma F, Thibout Y, et al. Impact of Silicone Stent Placement in Symptomatic Airway Obstruction due to Non-Small Cell Lung Cancer - A French Multicenter Randomized Controlled Study: The SPOC Trial. Respiration 2020;99:344-52.

11. Colt HG, Harrell JH. Therapeutic rigid bronchoscopy allows level of care changes in patients with acute respiratory failure from central airways obstruction. Chest 1997;112:202-6.

12. Murgu S, Langer S, Colt H. Bronchoscopic intervention obviates the need for continued mechanical ventilation in patients with airway obstruction and respiratory failure from inoperable non-small-cell lung cancer. Respiration 2012;84:55-61.

13. Bolliger CT, Sutedja TG, Strausz J, et al. Therapeutic bronchoscopy with immediate effect: laser, electrocautery, argon plasma coagulation and stents. Eur Respir J 2006;27:1258-71.

14. Macha HN, Becker KO, Kemmer HP. Pattern of failure and survival in endobronchial laser resection. A matched pair study. Chest 1994;105:1668-72.

15. Amjadi K, Voduc N, Cruysberghs Y, et al. Impact of interventional bronchoscopy on quality of life in malignant airway obstruction. Respiration 2008;76:421-8.

16. Oviatt PL, Stather DR, Michaud G, et al. Exercise capacity, lung function, and quality of life after interventional bronchoscopy. J Thorac Oncol 2011;6:38-42. 